\title{
Narradores transnacionais
}

\section{na ficção brasileira contemporânea}

Marcel Vieira Barreto Silva1

RESUMO: A questão das identidades vem, desde os anos 1980, ocupando lugar cada vez mais privilegiado no debate acadêmico. Além disso, nas últimas duas décadas, alguns escritos brasileiros inseriram essa questão como elemento central de composição de suas narrativas. Nosso intuito aqui é analisar como o problema das identidades desempenha função estrutural na forma dos romances Budapeste (Chico Buarque, 2003) e $O$ sol se põe em São Paulo (Bernardo Carvalho, 2007). Não se trata unicamente, portanto, de ver como o tema identitário aparece nas obras, mas de averiguar - no escopo da investigação estética - a maneira como a estrutura particular dos romances é construída em função dos problemas identitários enfrentados por seus narradores.

ABSTRACT: The question of identity has occupied a place more and more privileged in the academic debate since the 1980's. Moreover, in the last two decades, some Brazilian writers have pointed this issue as a central element in the composition of their narratives. We propose in this paper to examine how the issue of identity performs a structural function in the novels Budapeste (Chico Buarque, 2003) and $O$ sol se põe em São Paulo (Bernardo Carvalho, 2007). It is not only, therefore, to see how the theme of identity appears in these works, but to investigate - in the scope of the aesthetics research - how the particular structure of the novels is constructed on the basis of the identity problems faced by their narrators..

PALAVRAS-CHAVE: Identidade nacional; Literatura brasileira contemporânea; Chico Buarque, Bernardo Carvalho.

KEYWORDS: National Identity; Contemporary Brazilian Literature; Chico Buarque; Bernardo Carvalho

\section{Introdução}

No pensamento moderno, o que se revela no fundamento da história das coisas e da historicidade própria aos homens

\footnotetext{
${ }^{1}$ Doutorando UFF, contato: marcelvbs@hotmail.com
} 
é a distância que escava o Mesmo, é o afastamento que o dispersa e o reúne nos dois extremos dele mesmo. (Michel Foucault)

Imagens que sintetizam uma identidade nacional são ferramentas simbólicas que funcionam, pela sua característica discursiva - quase sempre - pedagógica, como uma estratégica retórica através da qual se 'imagina' a comunidade de uma nação. A composição desse repertório imagético - definido tanto pela atuação criativa dos artistas, quanto por investidas políticas diretamente interessadas em apresentar uma determinada imagem nacional - demonstra como os vários meios de representação simbólica (desde a pintura e a literatura, até o cinema e a televisão) estão preocupados com o tema, quais as particularidades midiáticas que circunscrevem os produtos concretos e como os próprios artistas articulam formalmente essas imagens identitárias. A literatura brasileira, como modalidade de representação artística historicamente situada na periferia dos fluxos capitalistas globais, lidou (e, de certa maneira, ainda lida) com esses anseios identitários, não apenas por sua condição subdesenvolvida (no sentido pauloemiliano), que a faz transitar - como numa gangorra - entre os influxos externos e as particularidades locais, mas, sobretudo, pela necessidade de marcar estética e politicamente sua singularidade em relação ao outro estrangeiro.

Um dos principais problemas teóricos acerca da literatura brasileira (e aqui, evidenciamos a nacionalidade, porque a questão identitária é central) está na necessidade (algumas vezes, obstinada e excessiva) da crítica de caracterizar especificamente a produção nacional enquanto material autêntico do país - ou seja, diferente do modelo europeu. Na tentativa de situar historicamente os momentoschave da literatura brasileira acerca das produções empenhadas em construir uma identidade nacional, Silviano Santiago (2004) propõe uma linha evolutiva (porém, devidamente nuançada), que parte da segunda metade do século XIX - obliterando, com isso, as epopeias indigenistas de frei Santa Rita Durão e de Basílio da Gama - até os 
debates em torno das políticas de identidade cultural de fins dos anos 1980.

De fato, Santiago situa sua reflexão na obra de Joaquim Nabuco, que fomenta na intelectualidade brasileira um sentimento de menoscabo ante a realidade do país - preferindo, antes, um olhar eurocêntrico para o liberalismo e as maravilhas modernas do velho continente. O autor, no entanto, retrocede para identificar tanto no movimento indigenista do Romantismo brasileiro (encabeçado por José de Alencar), quanto no 'Instinto de nacionalidade'2 de Machado de Assis, caminhos difusos de construção identitária, claramente marcados pelo embate forma e conteúdo. No caso da literatura nativista, o vocabulário típico do país, o assunto local e o influxo indigenista são signos que, junto a uma estrutura discursiva pedagógica, representam a união formalizada de local (indígena) e estrangeiro (português), simbolizada pelo casamento heterossexual da paixão romântica, que, como demonstra Doris Sommer (2004: p. 21), "forneceu uma retórica para os projetos hegemônicos, no sentido gramsciano de conquistar o adversário através do interesse mútuo, ou do 'amor', ao invés da coerção”.

A relação entre o nacional e o estrangeiro vai além da construção da trama em torno do contato colonial representado no romance indigenista. A presença dos modelos europeus de representação estética - da poesia byroniana ao romance realista - se manifesta, principalmente, na constituição formal das obras. Conforme aponta Roberto Schwarz (2000), durante a evolução das manifestações artísticas no Brasil, o aspecto fundamental relacionado à composição das obras foi a inadequação das formas importadas e a consequente dificuldade de ajustá-las à realidade do país, à sua matéria social. Com isso, o conteúdo temático brasileiro - suas imagens identitárias mais fortemente construídas - viu-se sempre ocupando uma forma de representação estrangeira, com suas retóricas expressivas e estruturas

2 Ensaio publicado em 1873, em que Machado de Assis pretende discutir os problemas do romance, teatro, poesia e lingua nacionais. 
simbólicas próprias, o que deixava 'as ideias fora do lugar'.

De fins do século XIX para fins do século XX, a ficção brasileira continuou seu embate formal em busca de emancipação estética e especificidade temática. Embora não seja a ambição deste artigo traçar os diversos momentos desse problema na literatura brasileira do último século, é importante notar que o romance contemporâneo, em boa medida, está ainda preocupado em narrativizar as relações entre o nacional e o estrangeiro, só que, agora, numa outra chave: ao invés de posicionar os aspectos locais em oposição aos influxos externos resultantes da colonização europeia (como a literatura de fins do século XIX), ou de assimilar do estrangeiro, via antropofagia, os elementos necessários para melhor representar o caráter nacional (como os modernistas de 1922 e a Tropicália nos anos 1960 e 1970), a ficção brasileira dos anos 1990 e, principalmente, dos anos 2000, relata histórias de choques culturais no panorama dos fluxos simbólicos do capitalismo globalizado. É o caso da relação do Brasil com a Hungria em Budapeste (Chico Buarque, 2003) e com a Inglaterra em Lorde (João Gilberto Noll, 2004). Além disso, procura entender as dinâmicas identitárias das comunidades diaspóricas que, desde fins do século XIX e início do século XX, encontraram no Brasil o lugar de chegada de suas jornadas de exílio, como os libaneses de Dois irmãos (Milton Hatoum, 2000) e os japoneses de O sol se põe em São Paulo (Bernardo Carvalho, 2007).

\section{BUDAPESTE: O CHOQUE CULTURAL E AS LÍNGUAS NACIONAIS}

Ao que tudo indica, José Costa, protagonista de Budapeste, é também seu narrador. Ele é um escritor fantasma, que, como tal, esconde sua identidade para que outros recebam publicamente os louros de seus escritos. Brasileiro, morador da zona sul do Rio de Janeiro (lugar, por sinal, extremamente associado à imagem do país no exterior), José Costa aos poucos se vê seduzido pelo canto de sereia da língua magiar. O contato do protagonista com a Hungria é casual e se 
relaciona diretamente com um signo do mundo contemporâneo: numa conexão de aeroporto, uma suspeita de bomba obriga os passageiros a desceram da aeronave e permanecerem uma noite em Budapeste. O estopim da relação entre José Costa e a capital húngara é narrado logo no início do livro, bem como suas questões fundamentais:

Desdobram-se, da leitura de Budapeste, dois problemas bem atinentes ao mundo contemporâneo: o da redefinição da questão de autoria, em tensão com as novas tecnologias de produção (e reprodução) de obras, e o da identidade cultural, que se impõe frente às tensões do mundo globalizado (FARIA, 2007, p.17).

Essas questões - intensamente imbricadas - vão modular a forma de composição do romance, que, para representar os efeitos do choque cultural na formação identitária do personagem, utiliza, além de outros, dois procedimentos estilísticos bastante nítidos: uma série de efeitos de duplicação das tramas e dos personagens e uma estrutura pendular de organização dos capítulos. Vejamos cada qual detalhadamente, analisando as estratégias retóricas e seus efeitos na economia expressiva do romance.

José Costa se confunde, e é por outros confundido, com vários personagens durante a história, criando uma série de duplos com significações específicas. Ele mesmo, em determinado momento, declara sobre sua condição: "Não me aborrecia caminhar assim num mapa, talvez porque sempre tive a vaga sensação de eu ser também o mapa de uma pessoa." (BUARQUE, 2003, p. 56) ${ }^{3}$ Ser um sendo outro, ser em si o caminho de uma jornada não sua, e ser, ao mesmo tempo, os dois e nenhum, é a principal característica do narrador de Budapeste.

Esses deslocamentos são operados não apenas na relação de José Costa consigo mesmo e com os demais personagens, mas dentro da própria instância narrativa, que se transmuta em 'outro' no fim do romance. Antes disso, porém, há uma série de personagens e eventos 'duplicados', em que a dinâmica da representação compõe um

\footnotetext{
${ }^{3}$ De agora em diante, as referências a Budapeste constarão apenas da paginação.
} 
movimento ondulatório entre Rio de Janeiro e Budapeste. Esse movimento é perceptível, inclusive, na organização dos capítulos: são sete no total; no primeiro, terceiro, quinto e sétimo predomina a ação na capital húngara; no segundo, quarto e sexto prevalece a trama em torno da capital fluminense. A instabilidade identitária do narrador é representada, estruturalmente, na forma pendular como a ação transita entre o Brasil e a Hungria, formalizando, portanto, um elemento temático dentro da estrutura particular do romance.

José Costa estabelece uma série de duplos, tanto na trama, como entre os personagens; ele próprio cria relações espelhadas com diversas figuras, inclusive ele mesmo. Rio de Janeiro e Budapeste, a língua portuguesa e a magiar, Vanda e Kriska, Joaquim e Pisti, o calor carioca e o frio húngaro, entre outros, são elementos espelhados que constroem esse panorama duplicado da vida de José Costa. No entanto, o protagonista se relaciona diretamente com três personagens, com os quais estabelece paralelismos espelhados em decorrência de sua atuação como escritor: Kaspar Krabbe, Kocsis Ferenc e o Sr... . Analisaremos, agora, as especificidades dessas relações e como elas contribuem para representar os deslocamentos identitários de José Costa.

O alemão Kaspar Krabbe, para quem José Costa escreve um romance autobiográfico, é uma figura proeminente nessa relação, que se configura em dois niveis: em primeiro lugar, o ato de escrever para e, principalmente, pelo outro faz com que José Costa incorpore, na própria organização dialógica da semântica da frase, a voz e a identidade do alemão. Em segundo lugar, José Costa passa a subsumir, ao encontrar em casa um exemplar autografado de $O$ ginógrafo (livro escrito por ele e assinado por Kaspar Krabbe), que o alemão tenha se envolvido com sua esposa Vanda. Esse ciúme imaginado leva o protagonista a assumir sua identidade. E assim, num instante de ira com Vanda, confessa o que estava engasgado há muito: "Naquele instante oco, com uma voz que não era minha, lhe comuniquei: o autor 


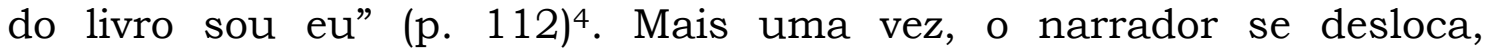
assumindo uma voz outra - não a sua - e revelando sua identidade mais intima e, por isso mesmo, mais frágil: ao denunciar a autoria, ele perde de vez a identidade - perde a esposa, o filho e qualquer ligação mais intrinseca que porventura haja com o Brasil.

Nos dois casos, é patente o processo de duplicação da voz narrativa, deslizando pelo complexo identitário do narrador. Esse procedimento pode também ser verificado na utilização do futuro do pretérito como uma estratégia de deslocamento radical entre José Costa (narrador) e José Costa (personagem): no plano da construção semântica, narrador e personagem - embora, até o último capítulo, sejam a mesma figura diegética -, deslocam-se um do outro, antecipando uma ruptura que, de fato, se aprofunda no capítulo derradeiro. Ao modular os verbos no futuro do pretérito, o narrador começa a fabular sobre o mundo, os demais personagens e, principalmente, sobre si mesmo, aventando possibilidades só vislumbráveis no plano imaginário da construção narrativa. Isso pode ser verificado no seguinte excerto:

O Álvaro insistia, me ligava a toda hora, a voz reverberando na agência vazia, e se eu fosse um sacana teria lhe sugerido que terceirizasse meu serviço. Eu sabia que seus rapazes o haviam abandonado um a um, roubado seus clientes, fundado prósperas agências onde se redigia de tudo, menos romances autobiográficos à altura dos meus. E se o fizessem, não só cobrariam uma fortuna, como exigiriam seu nome no topo da capa; afinal, pertenciam a essa nova classe de ghost-writers renomados, saiam até em fotos nas revistas, de braços com mulheres altas. Mas não mencionei os rapazes para o Álvaro, apenas lhe pedi que evitasse ligar tanto assim para a minha casa. $\mathrm{Eu}$ poderia precisar do telefone numa emergência, porque naqueles dias estava só com o menino e a babá, além disso a Vanda talvez quisesse se comunicar, ter notícias da família, dar seu novo endereço em São Paulo ou o número do seu celular. E quando ela telefonasse, eu aproveitaria para lhe dizer o quanto havia apreciado seu presente, me confessando surpreso pelo seu discernimento literário. Aí, desvanecida, ela discorreria sobre a influência da narrativa e as qualidades estéticas do livro, e tendo-

\footnotetext{
4 Grifo nosso.
} 
o à mão me leria parágrafos inteiros que havia sublinhado (p. 104-105).

Outro personagem com o qual José Costa mantém uma relação de espelhamento é o poeta húngaro Kocsis Ferenc, de fato, o único personagem que pertence aos dois mundos do protagonista: numa leitura pública e festiva no consulado da Hungria no Rio de Janeiro, Kocsis Ferenc é visto por José Costa, e, já em uma indicação proléptica, ocorre uma confusão entre os dois:

Mas assim que ousei empurrar a porta, o consulado explodiu em aplausos. Ato contínuo as cerca de cinquenta pessoas no salão, que estavam em pé, voltadas para a janela, se viraram para os lados e começaram a falar umas com as outras. Era a sonoridade do idioma húngaro que se abria para mim ao passo que eu penetrava o salão. Vibravam as vozes húngaras ao meu redor sem suspeitar que expunham a um intruso os seus segredos. (p. 35)

A relação espelhada entre José Costa e Kocsis Ferenc - aqui antecipada tempo-espacialmente na narrativa - será retomada perto do fim, no quinto capítulo, quando o brasileiro, de própria vontade, escreve um livro de poemas para ser assinado pelo decadente poeta húngaro. Esse fato é importante porque se trata de José Costa escrevendo em húngaro, e escrevendo versos, o que implica uma laboração muito intensa com a língua em seu estado mais bruto e particular. O sucesso da publicação (Tercetos secretos) e uma efusiva empolgação de José Costa com 'sua' obra - evidenciada pelo constante desejo do 'autor' em declamar 'seus' versos - é quebrada por certa objeção de Kriska:

Aí fiquei mordido, falei do prefácio do livro, assinado pelo professor Buzanszky Zoltán, falei das exaltações a Kocsis Ferenc que ouvira de gente graduada na fila de autógrafos. Pois bem, Kósta, há quem aprecie o exótico, disse Kriska. Exótico? Como, exótico? É que o poema não parece húngaro, Kósta. O que dizes? Parece que não é húngaro o poema, Kósta. Não me ofenderam tanto as palavras, quanto a cândida maneira como Kriska as pronunciou. E disse mais: é como se fosse escrito com acento estrangeiro, Kósta (p. 141, grifo nosso). 
A língua é um dos mais importantes signos identitários de qualquer nação, pois é nela que se escrevem as leis, que se relatam os grandes feitos históricos, e em torno da qual se mobilizam os mais diversos cidadãos, letrados ou não. "A língua portuguesa é a minha pátria", sentenciou o poeta português Fernando Pessoa. Para José Costa, possuir a lingua magiar, degluti-la em seu sotaque mais bem acabado, torná-la instrumento de composição lírica, é mais que um anseio de escritor expatriado: trata-se da formalização de sua identidade húngara, de sua completa assimilação às especificidades culturais budapestinas. Nesse sentido, Kocsis Ferenc é um duplo que medeia o envolvimento de José Costa com o idioma da Hungria, numa relação sempre conflitante, que se resolve, com um encaminhamento surpreendente, com o aparecimento do Sr... . Também escritor fantasma, com o qual José Costa se depara no encontro dos escritores anônimos sediado em Budapeste, o Sr... subitamente se torna uma extensão da vida do brasileiro na capital húngara: é ex-marido de Kriska, pai de Pisti, e, de fato, o escritor do romance chamado Budapest, capa furta-cor, do qual José Costa é o protagonista. O anseio desesperado de José Costa de se tornar outro, se tornar húngaro, de fato se materializa no Sr..., que representa o completo deslocamento da identidade do protagonista, numa satisfação insuspeita de ser o autor de um livro que não é seu, para melhor ser quem ele não é: "o autor do meu livro não sou eu" (p. 170).

Como vimos, o sentido de 'ser outro' é explicitamente apresentado no romance pelo trabalho exercido pelo narrador: está no fato de escrever em nome de outro, apagando sua identidade e vivendo na sombra de alguém que se apropria de suas potencialidades, e no esforço do narrador em assimilar (num exercício nem sempre muito tranquilo) uma língua estrangeira para, através da escrita, tornar-se outro. Assim, como brasileiro que aos poucos se torna húngaro (grafando, inclusive, o nome como Zsoze Kósta), o narrador, num jogo de espelho em abismo - construção heráldica às avessas, em que o brasão refletido é, na verdade, de outra família - deixa de ser 'um' para 
virar 'outro', um outro inominado (Sr...), também escritor fantasma, que transforma o outrora narrador em personagem, o 'eu' em 'outro': para enfim chegar ao ponto em que - deslocado da função de narrador para personagem e, por fim, para a de leitor - José Costa "lia o livro ao mesmo tempo que o livro acontecia” (p. 174).

\section{O SOL SE PÕE EM SÃO PAULO: ROMANCE NIPO-BRASILEIRO}

Yonsei, recém-divorciado, publicitário frustrado e ex-aluno de Letras - com um projeto estapafúrdio de tese de doutorado sobre o caráter premonitório da literatura - o narrador de O sol se põe em São Paulo encara a escritura do romance como uma forma de redenção de sua existência - da mesma forma como a velha japonesa, que o toma por escritor, narra-lhe sua história para reparar os erros do passado que a obrigaram a migrar para a capital paulista. $O$ narrador - em momento algum nomeado - envolve-se de tal maneira com a história contada pela japonesa, que a súbita interrupção do relato o obriga a sair numa investigação capaz de trazer não apenas os esclarecimentos surpreendentes do resto da história, mas, sobretudo, uma reflexão sobre sua própria condição identitária de bisneto de imigrantes.

Setsuko, a velha japonesa dona de restaurante, convida talvez fosse mais apropriado dizer convoca - o narrador para escutar o seu relato, e, a partir daí, escrever uma história que supostamente tenha ocorrido a ela antes de vir ao Brasil. No decorrer do romance, percebemos que nada é o que parece: de fato, a identidade dos personagens se consubstancia no conflito entre aparência e verdade, chegando ao ponto em que ser o outro é a maior coerência consigo mesmo: "o oposto é o que mais se parece conosco", vaticina o narrador no fim do livro.

Nesse sentido, a ascendência japonesa sempre pesou no narrador como a marca de uma fratura, que não deixa que ele seja brasileiro inteiramente (apesar de nascido e criado no país), nem japonês por completo, embora as referências familiares o levem a se 
imaginar nipônico. Em $O$ sol se põe em São Paulo, a velha japonesa escolhe o narrador (com a sua condição específica de Yonsei) para ser o redator de sua história por dois motivos: primeiramente, ela ouvira numa conversa de mesa, que o narrador era um escritor (dado importante não apenas para a adequada redação do livro, mas como elemento espelhado das histórias narradas, devido à presença de Junichiro Tanizaki, no passado, como um primeiro escritor dessa história); além disso, a senhora necessitava que o narrador nunca tivesse ido ao Japão, para que, com isso, só pudesse se relacionar com a história através da imaginação.

Como é que ela queria que eu escrevesse sobre um lugar onde nunca tinha posto os pés e que evitava com todas as forças? "O Japão que eu conheci não existe mais. Se eu quisesse dar o meu testemunho, podia contar sozinha. Preciso de alguém que nunca foi ao Japão. Preciso que você imagine. E o que você imagina nunca vai ser o que foi. Antes da guerra, a música mais tocada no Japão era o jazz. E isso eu tenho certeza de que você não podia imaginar" (CARVALHO, 2007, p. 3, grifo nosso). ${ }^{5}$

Além disso, a situação fractal do narrador se refere precisamente à construção de sua identidade nacional: ele está a duas gerações de uma origem japonesa (seus pais e seus avós nasceram e se criaram no Brasil), porém, sempre esteve marcado pela imaginação em torno do Japão, embora a relação com esse imaginário nunca tenha sido tranquila. Ele, em diversos momentos, demonstra uma repulsa à sua origem remota:

Durante muito tempo, eu tentei fugir como o diabo da cruz de tudo o que fosse japonês (vinha daí a minha repulsa e a minha ignorância da literatura japonesa). Eu podia nunca ter pisado no Japão, mas por muito tempo tentei acreditar que era onde ficava o inferno. (p. 29)

Como dado fundamental de composição do romance - dado esse, extremamente relacionado com os debates sobre identidade

${ }^{5}$ De agora em diante, as referências a $O$ sol se põe em São Paulo constarão apenas da paginação. 
cultural no mundo contemporâneo - a fratura identitária se manifesta na própria estrutura do romance em dois niveis: na maneira como os personagens assumem a identidade de outros (fato simbolizado, inclusive, pela presença do teatro kyogen) e - de modo semelhante a Budapeste - na organização estrutural dos capitulos. Em $O$ sol se põe em São Paulo, há dezoito capítulos simetricamente divididos, como a dobradiça de uma porta, como um livro aberto ao meio: os nove capitulos iniciais apresentam o narrador, seus problemas fundamentais (a ascendência japonesa, que, desde a infância, o colocou num embate identitário, e seu desejo frustrado de ser um escritor) e o posicionam como ponto de refração da história contada por Setsuko.

Quando está refratando esse relato, o narrador quase nunca cede a voz à japonesa, em discurso direto, mas conta a história de fora, com pouquíssima intervenção opinativa e se assemelhando, muitas vezes, a um narrador heterodiegético. Ao assumir essa voz discursiva, guiando a narrativa através do ponto de vista de Setsuko, o narrador homodiegético assume a identidade de um narrador heterodiegético com onisciência seletiva. Ou seja, como sua própria identidade fraturada, sua instância narrativa se altera devido à sua posição em relação à história.

Numa cena fundamental do relato da velha japonesa - em que se explica o modo como o pai de Jokichi articula a troca de identidades entre seu filho e um empregado, para que este vá à guerra em lugar daquele -, o narrador caracteriza a personalidade de Jokichi, deixando clara a marca do ponto de vista de Setsuko: "Por outro lado, Jokichi era um homem inteligente. Nada daquilo teria acontecido sem a sua cumplicidade, nem que fosse parcial. Era essa, ao menos, a convicção de Setsuko quando me contou a história" (p. 44, grifo nosso). Sua afirmação da inteligência de Jokichi é evidentemente mediada pela opinião de Setsuko.

Logo em seguida, no entanto, o narrador começa a opinar em torno da personalidade e do pensamento de Jokichi, não apenas sem denunciar a marca opinativa de Setsuko, mas relatando o ponto de 
vista de Jokichi e, inclusive, de seu pai, num esforço de tornar ambígua a modulação da instância narrativa:

É claro que ele tinha percebido que o pai o mandava para o interior para afastá-lo da guerra. E, se acatou a decisão, não foi só por respeito filial. No fundo, também não compartilhava do espírito militarista. $\mathrm{O}$ alistamento teria sido apenas um pretexto para se afastar da opressão familiar. [...] Sem nunca ter dito nada, o pai tomou a iniciativa de corresponder o desejo que reconhecera no filho (p. 44, grifo nosso).

Esse procedimento sutil de alteração das atribuições da entidade narrativa - entre o foco limitado do narrador homodiegético e a refração típica do narrador heterodiegético com onisciência seletiva corrobora a condição fractal da identidade do narrador. É importante lembrar que, em O sol se põe em São Paulo, há, de forma mais direta, duas histórias que se inter-relacionam através de processos narrativos: Setsuko conta ao narrador a história que vive e ouviu de Michiyo, e o narrador conta ao leitor a história que vive e ouviu da velha japonesa. Esses dois momentos estão, como já começamos a argumentar, representados formalmente pela organização estrutural dos capitulos.

Os nove capitulos subsequentes desmontam, pouco a pouco, a construção da trama delineada na metade inicial do livro: a velha japonesa desaparece (sua casa é demolida) e uma investigação do narrador - que não suporta a ausência de um fim para a história começa a re-significar os eventos narrados por Setsuko (que, na verdade, não existe): ela é, na verdade, uma personagem de si mesma criada por Michiyo, uma identidade outra assumida para servir de ponto de articulação da trama. Esse procedimento de alteração das identidades é bastante recorrente no romance: Michiyo que se passa por Setsuko, Seiji que se passa por Jokichi, que, por sua vez, se passa por Teruo, o primo do Imperador que se passa por Seiji, Masukichi que se passa por raposa, no kyogen. Porém, no fim das contas, a principal mudança identitária é entre os personagens e si mesmos, sempre sendo outros para, no fundo, se parecerem cada vez mais consigo próprios. 
Aqui, a função do teatro é determinante, pois, como os atores no palco kyogen: ao incorporar o papel da raposa a seus movimentos naturais, passam a não carecer mais da máscara para recordar ao público quem ele é. Ou seja, ser e representar se fundem, o eu e o outro se coadunam, sendo ambos conciliados pelo não-ser do corpo agora duplicado: "Por mais longe que você vá, por mais que tentem confiná-lo a um papel e a um lugar que não são seus, você sempre leva as máscaras consigo. [...] No fundo, todas as máscaras confirmam quem você é. Pois é você que as usa" (p. 155-156).

Nessa segunda parte do livro, ocorre a transformação do narrador, pois ele se vê obrigado a viajar ao Japão para concluir o seu relato: "Só me restava voltar para onde eu nunca tinha ido" (p. 104). Essa frase é sintomática do sentimento do narrador em relação ao Japão, pois, embora nunca tenha ido ao país, sua viagem tem um sentido íntimo, profundo e arraigado de retorno: retorno ao país imaginado, à pátria construída pelos símbolos familiares, pela presença constante da ausência.

Segundo o mapa do hotel que a minha irmã tinha me mandado e no qual também não havia nenhuma palavra que não estivesse em japonês, àquela altura eu já devia ter atravessado um canal. Mas não havia canal nenhum. Por estar representado em azulclaro, o canal era a minha única referência num mapa todo escrito numa lingua de que sempre tentei escapar, por achar que ela pudesse me condenar a ir aonde eu não queria. (p. 106, grifo nosso).

De fato, a língua é um dos maiores signos de uma nação. E o narrador de $O$ sol se põe em São Paulo é muito ciente da importância que uma língua nacional desempenha na formação identitária do indivíduo. Nesse sentido, ele não apenas se afasta da língua japonesa por acreditar que ela, de certa forma, vá religá-lo à origem remota da qual ele quer se afastar -, mas também reconhece que uma maneira de demarcar o seu pertencimento em relação ao Brasil é escrever em sua língua. 
A minha obsessão não era um capricho, era uma loucura. Se no inicio ainda podia parecer uma veleidade adolescente, com os anos acabou se revelando uma reação natural à constatação de que eu tinha esgotado todas as chances de fazer parte deste mundo, de me sentir integrado a ele, e que não bastava falar português, era preciso escrever também, para não correr o risco de algum dia ter de pisar no Japão, por necessidade, sem conseguir dizer mais que duas palavras em japonês, como a minha irmã, eu disse ao homem com lábio leporino, em inglês, quando comecei a contar a história. (p. 19-20)

A relação do narrador com o Japão passa por uma profunda re-significação quando ele aporta no país. De início, ele estranha o fato das pessoas o tratarem mal por não ser japonês, algo que (pela aparência do Yonsei) só é perceptível através da língua:

Eu estava perdido. Resolvi pedir informação a alguém - não havia um único ocidental nas ruas. Me dirigi a um homem de terno, em inglês. $\mathrm{E}$, se num primeiro instante ele chegou a mostrar alguma boa vontade, fugiu de mim assim que percebeu que eu era estrangeiro. (p. 106)

Porém, aos poucos ele se dá conta do grau de relação que possui com aquele lugar e aquelas pessoas, do envolvimento simbólico que ele partilha com o que o cerca. Sente-se acolhido - intimidade imaginada num lugar que o tomam por estrangeiro: "Era domingo, e havia pouca gente nas ruas. $\mathrm{O}$ ar frio batia no meu rosto. Embora eu nunca tivesse pisado ali, tudo era reconhecimento, como se eu estivesse voltando para casa." (p. 122, grifo nosso).

Nesse sentido, a construção da identidade nacional do narrador se dá através de um processo conflituoso, em que, embora nascido e criado no Brasil - falando e escrevendo em sua língua -, percebe-se partilhando signos identitários com o Japão. Ele não é simplesmente um exilado diaspórico que retorna ao lar, mas um indivíduo que, ainda que estabeleça relações intrínsecas e diretas com a sua terra natal, está invariavelmente ligado ao país de seus antepassados, cuja memória lhe foi transmitida - na forma de signos partilhados - durante a sua formação. 
Assim, ao re-significar a história que a velha japonesa vinha lhe relatando, o narrador passa a refletir sobre o sentido da sua própria identidade nipo-brasileira. Não se trata do movimento simples de 'escolher' a que país vai oferecer o seu envolvimento identitário: como numa gangorra desequilibrada, entre Japão e Brasil, o sentido de pertencimento do narrador transita descompassado, em que ser o que não é significa tornar-se o que sempre foi.

Quis me tornar um escritor, o que não sou. E me fazer escrever na frente de batalha, 'onde a civilização encontra a barbárie e deixa entrever o que dela traz em si', nesta cidade que não pode ser o que é, uma história de homens e mulheres tentando se fazer passar por outros para cumprir a promessa do que são: um ator a quem proíbem atuar; um homem que precisa deixar de ser quem é para lutar pelo país que o rejeita; outro que já não pode viver com o próprio nome, pois morreu numa guerra de que não participou; uma mulher que só ama quando não podem amá-la; um escritor que só pode ser enquanto não for. Uma história de párias, como eu e os meus, gente que não pode pertencer ao lugar onde está, onde quer que esteja, e sonha com outro lugar, que só pode existir na imaginação em nome da qual ela me contou uma história que pergunta sem parar a quem a ouve como é possivel ser outra coisa além de si mesmo. (p. 163-164)

Com isso, mais que decidir entre um ou outro lado de sua formação identitária (Brasil ou Japão), o narrador se assume como indivíduo fraturado: ele descobre, no fim, que a única maneira de apaziguar sua condição fractal é vivê-la assim, permanentemente, como o outro de si mesmo. Pois, como na explicação que o estrangeiro dá à filha adolescente sobre o principio de um jardim zen no monte Koya, a identidade do narrador é a extensão de sua existência num lugar aonde ele nunca foi:

Tudo é marca do homem. Foi ele quem fez este jardim. Tudo é artificial, mas a marca do homem já não está aí. Ele desenhou o jardim, arou a areia e desapareceu sem deixar rastros, embora o próprio jardim não seja outra coisa além do vestígio da sua passagem. (p. 119)

\section{Considerações finais}


As reflexões em torno das identidades culturais na contemporaneidade nos permitem compreender como os indivíduos se posicionam perante o mundo, na ordem do capitalismo tardio, dos fluxos migratórios, das mobilidades espaço-temporais dos meios de comunicação digitais, dos caminhos entrecruzados das correntes simbólicas. Como tal, são resultado direto do recrudescimento da globalização como um processo de integração dos mercados nacionais, a fim de quebrar as barreiras comerciais entre os países e penetrar cada vez mais largamente nos espaços regionais - os quais, por conseguinte, criam movimentos de manutenção das tradições e preservação das identidades locais.

Nesse sentido, é curioso perceber que as causas e consequências da globalização e dos fluxos simbólicos mundiais não se tornam questões fundamentais em Budapeste e $O$ sol se põe em São Paulo: por outro lado, elas são tomadas a priori, como dado concreto do mundo atual, para se investigar um sentimento mais individual, que é o sentido de pertencimento dos narradores transnacionais a partir da fratura identitária com que se deparam no decorrer dos romances. Dessa forma, podem ser caracterizados como intimistas, pela ênfase que dão aos movimentos internos dos personagens quanto à constituição de suas identidades nacionais.

O José Costa de Budapeste e o narrador de $O$ sol se põe em São Paulo são semelhantes quanto à relação que estabelecem com os países em que não nasceram, porém, com uma diferença fundamental: José Costa passa a se relacionar com a Hungria por acaso, numa conexão de aeroporto voltando para o Brasil, enquanto que o outro é descendente de imigrantes, e tem com o Japão uma relação que parte da repulsa à origem remota, até se tornar, no fim do livro, numa sentença de reconhecimento da sua condição fractal, que nunca permitirá a ele se sentir filho de apenas uma nação.

Assim, ao narrar histórias de personagens que escrevem em nome de outros e de individuos que assumem outras identidades para 
sobreviver e se redimir pela escrita, Budapeste e $O$ sol se põe em São Paulo se inserem como romances intimamente relacionados com a experiência dos homens em suas terras e com o seu tempo.

\section{Referências bibliográficas}

ANDERSON, Benedict. Nação e consciência nacional. São Paulo: Ática, 1989.

CANDIDO, Antonio. "Dialética da malandragem: caracterização das Memórias de um sargento de milícias." in: Revista do Instituto de Estudos Avançados [IEB/USP]. São Paulo, n.8, p. 67-89, 1970.

. Literatura e sociedade: estudos de teoria e história literária. 8.ed. São Paulo:

T. A.Queiroz, 2000. (Biblioteca de letras e ciências humanas - Série 2a, Textos; 9) CARVALHO, Bernardo. O sol se põe em São Paulo. São Paulo: Companhia das Letras, 2007.

FARIA, Alexandre. "Budapeste, ou a inversão de Babel." in: DEALTRY, Giovanna et alii (org.). Alguma prosa: ensaios sobre literatura brasileira contemporânea. Rio de Janeiro: 7Letras, 2007. p. 15-26.

FOUCAULT, Michel. "O homem e seus duplos." in:_. As palavras e as coisas. São Paulo: Martins Fontes, 1999. p. 417-473.

HALL, Stuart. A identidade cultural na pós-modernidade. 11 ed. Rio de Janeiro: DP\&A, 2006.

HOLLANDA, Francisco Buarque de. Budapeste. São Paulo: Companhia das Letras, 2003.

SANTIAGO, Silviano. O cosmopolitismo do pobre: crítica literária e crítica cultural. Belo Horizonte: UFMG, 2004.

SCHWARZ, Roberto. Ao vencedor as batatas: forma literária e processo social nos inícios do romance brasileiro. São Paulo: Duas Cidades, Ed. 34, 2000. (Col. Espírito Crítico).

Que horas são? São Paulo: Companhia das Letras, 1987.

SOMMER, Doris. Ficções de fundação. Belo Horizonte: UFMG, 2004. 